\title{
Viscosity of plasticized sulfur-extended asphalt: two-factor sequential optimization
}

\author{
Vitaliy Gladkikh ${ }^{1, *}$,Evgeniy Korolev ${ }^{1}$, Valentina Gladkikh$^{2}$, Ilya Sukhachev ${ }^{3}$ \\ ${ }^{1}$ Moscow State University of Civil Engineering, Yaroslavskoe shosse, 26, Moscow, 129337, Russia \\ ${ }^{2}$ Orenburg State University, Pobedyave.13, Orenburg, 460018, Russia \\ ${ }^{3}$ Tyumen Industrial University, Volodarskogo str., 38, Tyumen, 625000, Russia
}

\begin{abstract}
The compounding properties of construction materials for pavements strongly depend on dynamic viscosity of the binder. The favorable class of binder is plasticized sulfur-extended asphalt. Unfortunately, the viscosity of such a binder has not been studied in detail. In the present work we have performed experimental two-factor sequential constrained optimization of the viscosity. The binders under examination were made of asphalt, sulfur and paraffin. It was revealed that the addition of sulfur and paraffin leads to a significant decrease of the dynamic viscosity. The obtained results allowed us to estimate mixture and temperature that correspond to optimal compounding properties of the sulfur-extended asphalt concrete. In particular, for plasticized asphalt concrete with $30 \%$ of sulfur and $5 \%$ of paraffin, the optimal processing temperature is $25{ }^{\circ} \mathrm{C}$ lower than for ordinary asphalt. Since low preparation temperatures correspond to low emission of toxic gases and low processing costs, we can consider the concretes that will be based on plasticized sulfur-extended asphalt as green paving materials.
\end{abstract}

\section{Introduction and prior work}

Current research directed to the design of new construction materials for pavements revealed that the materials based on sulfur-extended asphalt are of high physicalmechanical and operational properties. In particular, such materials are characterized by high resistance to rutting, extended fatigue life and corrosion resistance [1-15].

Compounding properties of asphalt concrete mixtures strongly depend on dynamic viscosity of the binder - the asphalt (bitumen). The viscosity is the fundamental property of the binder and it is one of the most important compounding properties that directly affect the conditions and quality of mixing, laying and compacting of the asphalt concrete. The viscosity is mostly determined by the temperature. Temperatures of preparation and laying of asphalt concrete mixtures should be selected so that the viscosity of the binder at this temperature was close to optimal. Increased temperatures, being preferable for laying, at the same time conduct to increased cost of preparation and induce extra emission of toxic gases. It was revealed during years of experience in road construction that in order to allow pumping by asphalt pumps, dosing and proper mixing with mineral materials the value of

* Corresponding author: gladkich 87@mail.ru 
viscosity of binder should be less than $0.5 \mathrm{~Pa} \cdot \mathrm{s}$, and the optimal viscosity is near $0.2 \mathrm{~Pa} \cdot \mathrm{s}$ (during laying, the optimal viscosity is near $20 \mathrm{~Pa} \cdot \mathrm{s}$.) These values, when compared with the viscosity of asphalt at normal conditions (about $0.1 \mathrm{GPa} \cdot \mathrm{s}$ ), immediately show how important it is to select the appropriate temperature.

It was also stated that dynamic viscosity of the concrete mixture can be efficiently controlled by means of sulfur admixtures $[16,17]$. Still, such an important parameter as the viscosity of plasticized sulfur-extended asphalt has not been studied in detail. Particularly, authors of [16] have only studied the influence of small amounts of sulfur. In the present work we have examined the dependencies between viscosity of plasticized sulfur-extended asphalt, temperature and content of the sulfur and plasticizer; this allowed us to estimate the mixture and temperature that correspond to the best compounding properties.

\section{Materials and methods}

The viscosities of the sulfur-extended asphalts were measured by rotational viscometerMCR 101 [18] that is produced by Anton Paarand equipped with Peltier temperature control system for concentric cylinder geometries [19]. Such temperature control system meets the standard test method ASTM D 4402 [10]. The viscometer consists of stationary cup and rotating bob. Such viscometers are described in detail in e.g. [21]. The related figure is Fig. 4.3 on page 151 in [21]; the only difference is the bob is rotating part. The viscosity is determined by measuring the torque required to maintain a constant rotational speed of the cylindrical bob, when the bob plunges into sulfur-extended asphalt at a constant temperature. The measured value of the torque depends on the viscosity of the sample of binder, thus allowing to determine the viscosity. In turn, measurements made with rotational viscometer allow to predict real field performance of the binder under the operational conditions.

Sulfur-extended asphalts were prepared with grade 60/90 bitumen and technical sulfur. The content of sulfur was ranged from 5 to $60 \%$. The viscosity measurements were carried out at various temperatures - from 120 to $160{ }^{\circ} \mathrm{C}$.

\section{Results and discussion}

Minimum temperature during viscosity measurement was $120{ }^{\circ} \mathrm{C}$.Such value was chosen because of the sulfur melting temperature $\left(119{ }^{\circ} \mathrm{C}\right)$.Maximum temperature was selected on the basis of the fact that above $158{ }^{\circ} \mathrm{C}$, due to changes in molecular structure, the viscosity of sulfur melts begins to increase(Figure1); thus, we can expect that processing characteristics of sulfur-extended asphalt will be degraded at high temperatures (not to mention the increased cost of production).

Furthermore, as it was already shown [22, 23] and also mentioned above, elevated temperature of the sulfur extended-asphalt leads to increasing in both $\mathrm{SO}_{2}$ and $\mathrm{H}_{2} \mathrm{~S}$ emission. This is due to the increase in the vapor pressure of sulfur at higher temperatures (Figure2, 3) [24]. The saturated vapor pressure begins to rise quickly if temperature of the melt exceeds $140{ }^{\circ} \mathrm{C}$.

The vaporized sulfur is subject to active air oxidization, thus the concentration of sulfur dioxide increases significantly. Also, the elevated temperature of the mixture leads to elevated degree of dehydrogenation of the asphalt and, consequently, intensifies the hydrogen sulfide formation. Therefore, in order to ensure occupational health and safety requirements, the maximum temperature of the sulfur melt was selected to be $160{ }^{\circ} \mathrm{C}$ during examination of rheological characteristics. 


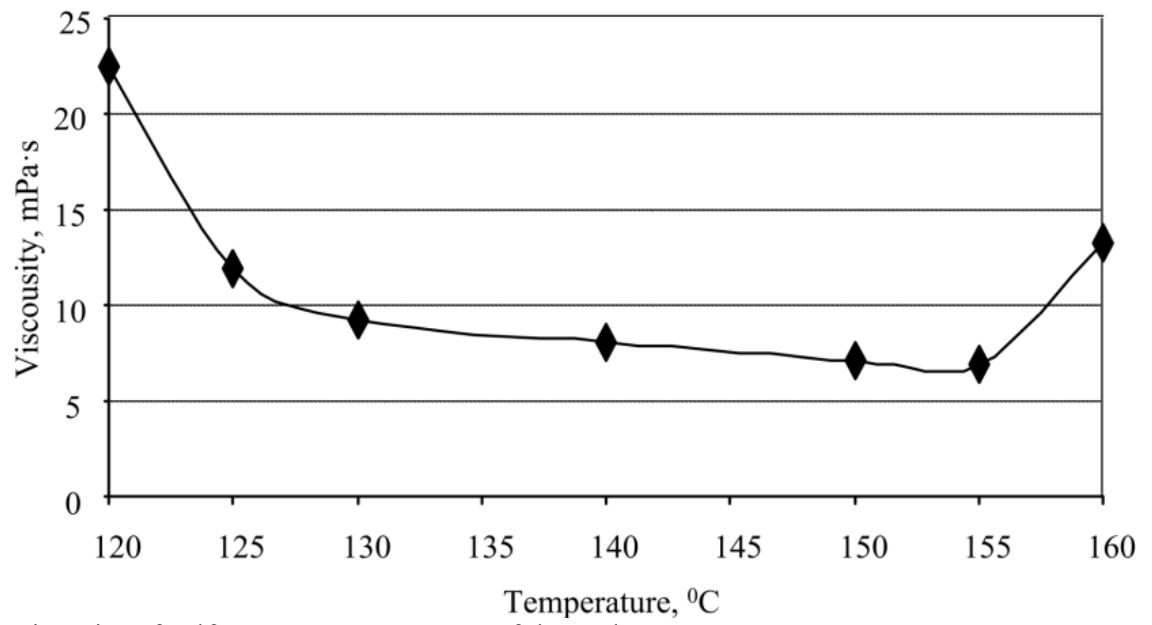

Fig. 1.Viscosity of sulfur versus temperature of the melt.

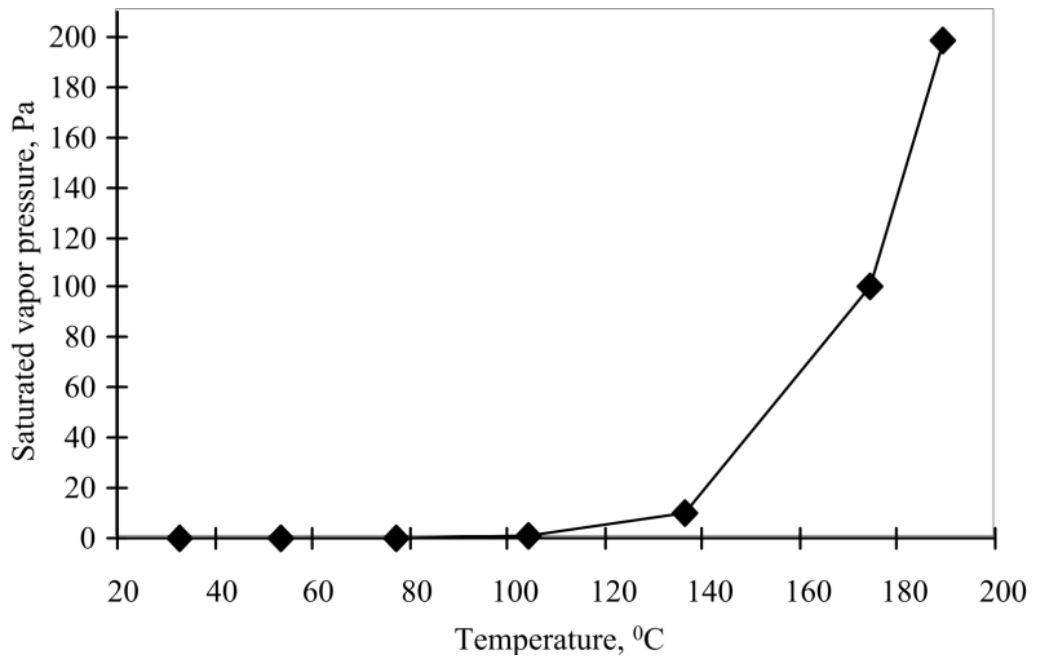

Fig. 2.Dependence between saturated vapor pressure and temperature of the sulfur melt.

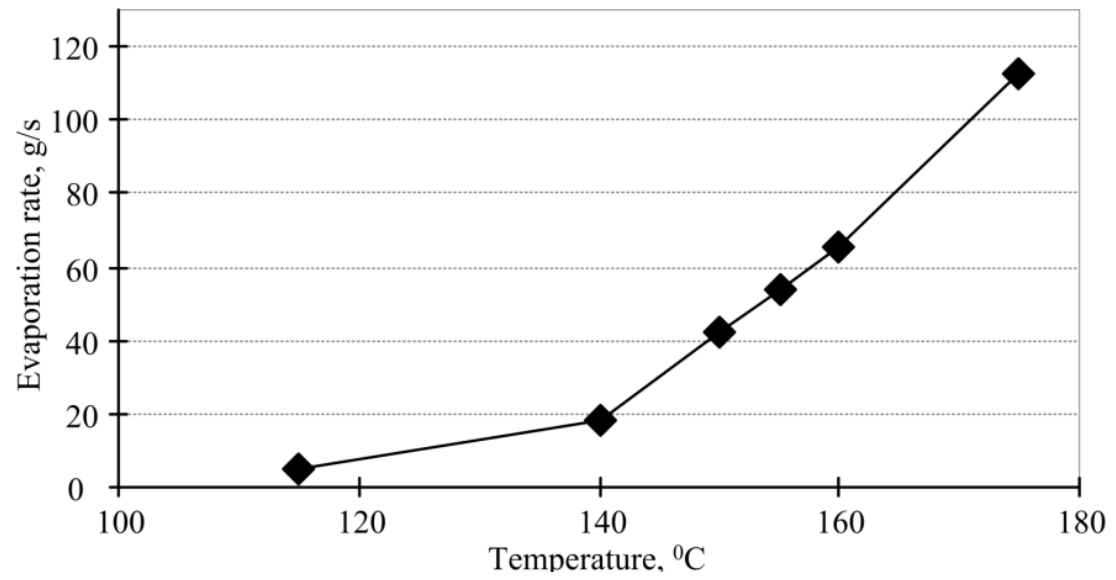

Fig. 3.Dependence between evaporation rate and temperature of the sulfur melt. 
The results of viscosity measurements for different temperatures and amounts of sulfur in sulfur-extended asphalt are presented on Figure 4.

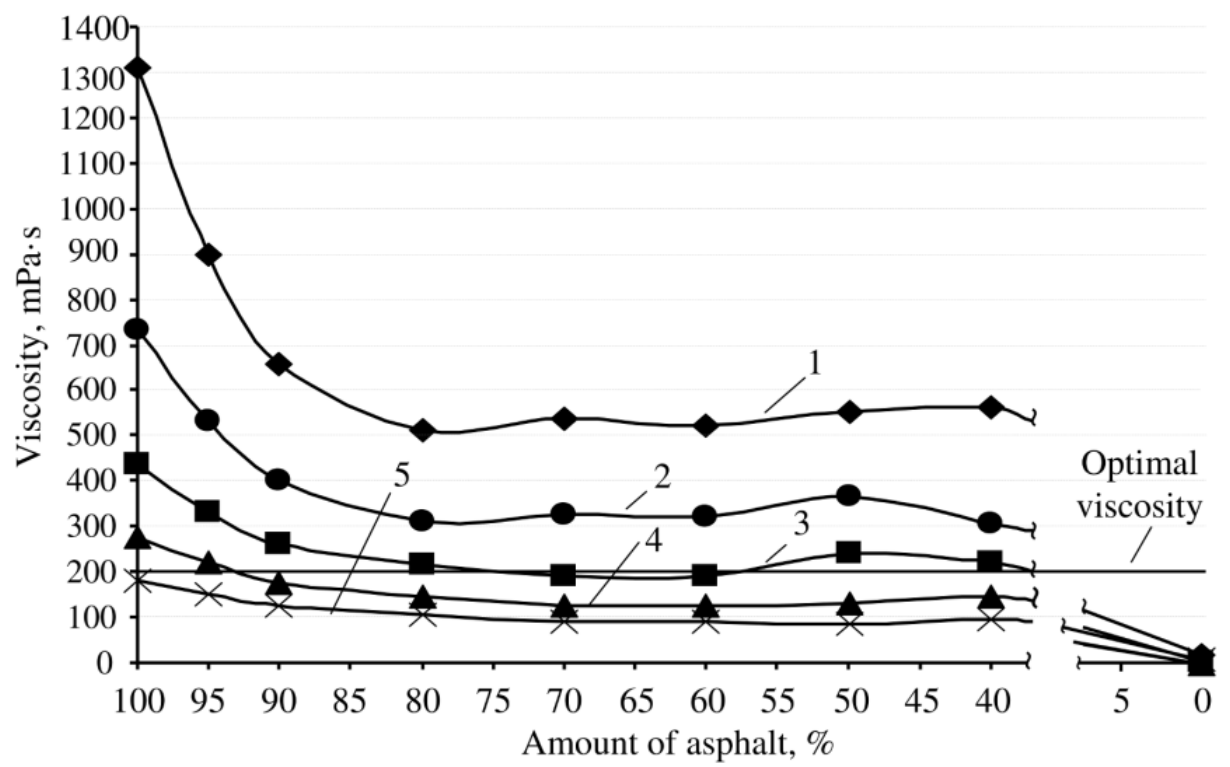

Fig. 4.Viscosity of sulfur-extended asphalts with different amounts of sulfur $\left(1-120{ }^{\circ} \mathrm{C} ; 2-130{ }^{\circ} \mathrm{C}\right.$; $\left.3-140{ }^{\circ} \mathrm{C} ; 4-150{ }^{\circ} \mathrm{C} ; 5-160{ }^{\circ} \mathrm{C}\right)$.

As it follows from Figure 4, addition of sulfur to asphalt causes noticeable decrease in viscosity of the binder. In particular, viscosity of the sulfur-extended asphalt that contain $5 \%$ of sulfur is 1.5 and 1.3 times lower than the viscosity of the asphalt at the 120 and $150{ }^{\circ} \mathrm{C}$, respectively.

Highest rate of change in viscosity of sulfur-extended asphalt is observed when amount of sulfur is enlarged up to $10 \%$. This is probably due to dissolving of sulfur in the melted asphalt. The minimal viscosity is achieved for the sulfur content between 20 and $40 \%$. Namely, viscosity of the sulfur-extended asphalt that contain $20 \%$ of sulfur is 2.6 and 1.9 times lower than the viscosity of the asphalt at the 120 and $150{ }^{\circ} \mathrm{C}$, respectively; for the $30 \%$ of sulfur such values are 2.4 and 2.2 , respectively.

Optimal viscosity $\eta_{\text {opt }}=0.2 \mathrm{~Pa} \cdot \mathrm{s}$ of the sulfur-extended asphalt can be achieved at various temperatures for the different amounts of sulfur(Table 1).

Table 1. Temperatures that correspond to the optimal viscosity of the sulfur-extended asphalt with different amounts of sulfur.

\begin{tabular}{|c|c|c|c|c|c|c|c|c|}
\hline Amount of sulfur, \% & 0 & 5 & 10 & 20 & 30 & 40 & 50 & 60 \\
\hline Temperature, ${ }^{0} \mathrm{C}$ & 158 & 152 & 147 & 142 & 139 & 139 & 143 & 144 \\
\hline
\end{tabular}

Again, it should be noted that the positive effect of sulfur on the viscosity of the sulfurextended asphalt is mostly noticeable at lower temperatures (that are close to $120{ }^{\circ} \mathrm{C}$ ). In particular, for the admixture of $10 \%$ of sulfur: the viscosity of the sulfur-extended asphalt is 2 times lower than viscosity of asphalt at $120{ }^{\circ} \mathrm{C}(650 \mathrm{mPa} \cdot \mathrm{s}$ and $1300 \mathrm{mPa} \cdot \mathrm{s}$, respectively $)$ and only 1.1 times lower at $140{ }^{\circ} \mathrm{C}(380 \mathrm{mPa} \cdot \mathrm{s}$ and $420 \mathrm{mPa} \cdot \mathrm{s}$, respectively). 
To reduce the temperatures of preparation and paving of asphalt concrete it is also advisable to use various plasticizers. Obviously, the plasticizers used during production and laying of sulfur-extended asphalt concretes must meet a number of extra requirements. In particular, the emission of toxic gases that originating during reaction between sulfur and asphalt should be minimized. It is already known from the various research works that paraffin cane successfully be used as such plasticizer $[25,26]$. The paraffin, aside from plasticizing the sulfur-containing mixture, reduces the brittleness of sulfur and prevents crystallization during cooling. During reaction between sulfur and paraffin, some amount of polymer sulfur is formed. The polymer sulfur, if compared with crystal modifications of sulfur, is characterized by high adhesion to fillers and also by high deformability and tensile strength; internal stresses at the transition from liquid to solid are less for polymer sulfur.

We have examined the effect of the paraffin on the viscosity of sulfur-extended asphalt. The composition sulfur-extended asphalt with $30 \%$ sulfur was used as reference composition. Since the price of the paraffin is relatively high, the amount of paraffin is limited by $10 \%$.

It is revealed the supplementary admixture of paraffin leads to a noticeable decrease of viscosity (Figure5).

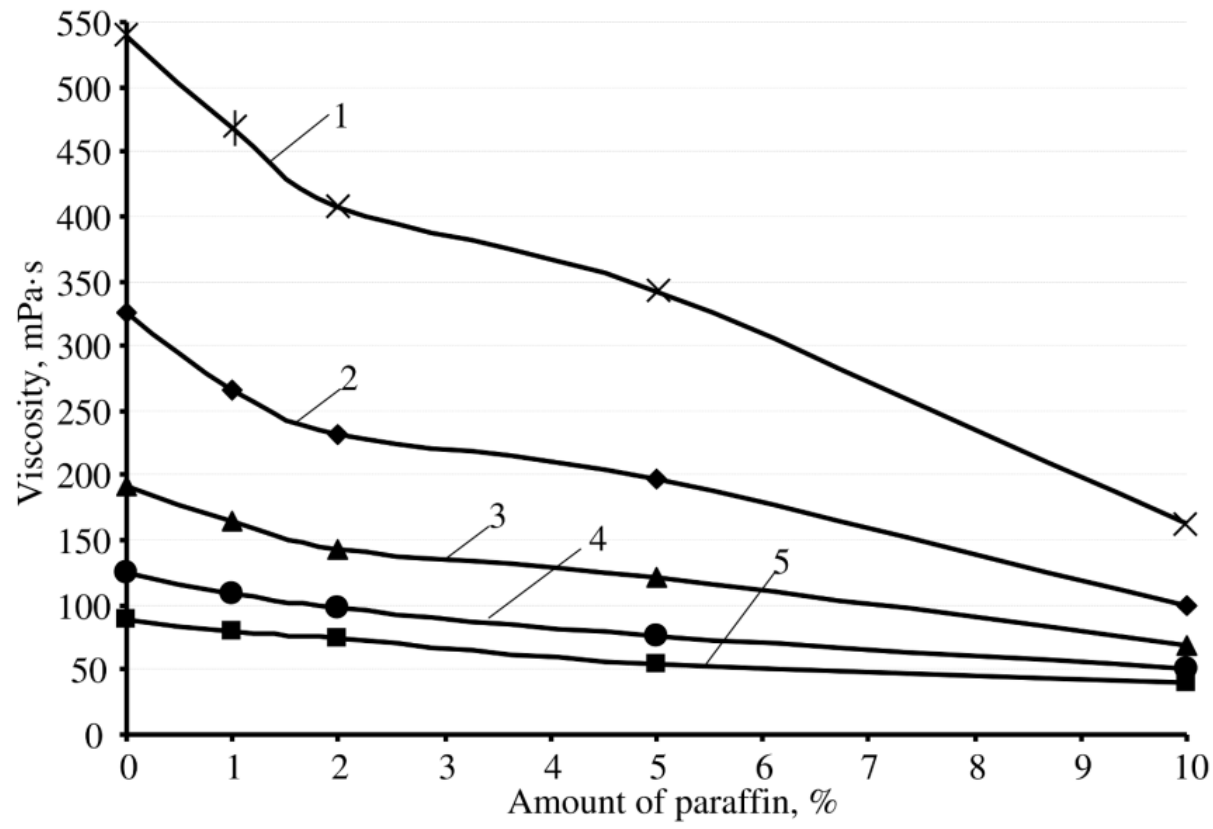

Fig. 5.The dependence between viscosity of sulfur-extended asphalt and content of the paraffin (1 $\left.120{ }^{\circ} \mathrm{C} ; 2-130{ }^{\circ} \mathrm{C} ; 3-140{ }^{\circ} \mathrm{C} ; 4-150{ }^{\circ} \mathrm{C} ; 5-160{ }^{\circ} \mathrm{C}\right)$.

The viscosity of plasticized sulfur-extended asphalt with $2 \%$ of paraffin at temperatures from 120 to $160{ }^{0} \mathrm{C}$ is $1.2-1.4$ times lower than the viscosity of the reference sulfurextended asphalt; for $5 \%$ of paraffin these values are 1.6-1.7, and for $10 \%-2.2-3.3$.

Optimal viscosity $\eta_{\text {opt }}=0.2 \mathrm{~Pa} \cdot \mathrm{s}$ of the plasticized sulfur-extended asphalt $(30 \%$ of sulfur) can be achieved at various temperatures for the different amounts of paraffin (Table 2). 
Table 2. Temperatures that correspond to the optimal viscosity of the plasticized sulfur-extended asphalt with different amounts of paraffin.

\begin{tabular}{|c|c|c|c|c|c|}
\hline Amount of paraffin, \% & 0 & 1 & 2 & 5 & 10 \\
\hline Temperature, ${ }^{0} \mathrm{C}$ & 139 & 137 & 134 & 130 & $<120$ \\
\hline
\end{tabular}

\section{Summary and conclusion}

As it follows form the experimental results, the addition of sulfur leads to a significant decrease of the dynamic viscosity of non-plasticized sulfur-extended asphalt. The range from 0 to $10 \%$ of sulfur corresponds to the highest rate of change; this is quite consistent with the data on the solubility of sulfur in asphalt. It was found that the optimal viscosity $\eta_{\text {opt }}=0.2 \mathrm{~Pa} \cdot \mathrm{s}$ that corresponds to the best compounding properties (that are characterized by efficiency of mixing the mineral dispersed phases with binder) can be achieved at 140 ${ }^{0} \mathrm{C}$. In comparison with similar temperature for traditional asphalts, the obtained value is about $15{ }^{\circ} \mathrm{C}$ lower - even for non-plasticized composition with both 30 and $40 \%$ of sulfur. The former content can be considered as optimal.

On the second stage of the research, the paraffin is used as plasticizer. This allowed us to lower the temperatures even further. In particular, for the $5 \%$ of paraffin, the processing temperature can be lowered by $10{ }^{\circ} \mathrm{C}$ while the compounding properties are maintained at best level. Since low preparation temperatures correspond to low emission of toxic gases and low processing costs (e.g., the energy consumption is reduced by 10 to $15 \%$ ), we can consider the concretes that will be based on plasticized sulfur-extended asphalt as green paving materials.

In the present work we have performed experimental simplified two-factor sequential constrained optimization of the viscosity of sulfur-extended asphalt. The predictor variables are amounts of sulfur and plasticizer; the temperature that correspond to the optimal viscosity $\eta_{\text {opt }}=0.2 \mathrm{~Pa} \cdot \mathrm{s}$ was the response variable. The simplification is in that the only two steps are performed along each predictor, and price of the components are taken into account rather intuitively and informal (high limit of $10 \%$ for paraffin). Despite this simplified scheme, the obtained results allowed us to estimate mixture and temperature that correspond to optimal compounding properties. In further work, we are planning to perform statistically correct optimization that involves both experiments and regression procedures.

This work is supported by grant of Russian Federation President SP-2627.2016.1.

\section{References}

1. Yu.E. Vasil'ev, O.A. Voeyko, D.S. Tsar'kov, Naukovedenie Online Journal, 5 (2014)

2. A.Yu. Fomin, V.G. Khozin, Building Materials, 11 (2009)

3. M. Mazumdar, S.K. Rao, Transportation Research Record, 1417 (1993)

4. V.A. Gladkikh, E.V. Korolev, D.L. Khusid, Building Materials, Equipment and Technology of XXI century, 3 (2015) 
5. V.A. Gladkikh, E.V. Korolev, D.L. Khusid, News of Moscow State University of Architecture and Construction, 12 (2016)

6. V.M. Prikhod'ko, Yu.E. Vasil'ev, Industrial and Civil Engineering, 12 (2014)

7. O.I. Doshlov, I.A. Kalapov, News of IrkutskStateTechnicalUniversity, 11 (2015)

8. V.A. Gladkikh, E.V. Korolev, V.A. Smirnov, I.Sukhachev, Procedia Engineering, 165 (2016)

9. V.A. Gladkikh, E.V. Korolev, I.Sukhachev, MATEC Web of Conferences, 86 (2016)

10. P. Qian, H. Qiao, Q. Ma, Journal of SoutheastUniversity (Natural Science Edition), 39 (2009)

11. J. Colange, D. Strickland, G. McCabe, K. Gilbert, R. May, S. Banbury, Asphalt mixtures modified with sulphur pellets, impact on pavement thickness, Road Materials and Pavement Design, 11 (2010)

12. A. Cocurullo, J. Grenfell, N.I. MdYusoff, G. Airey, RILEM Bookseries, 4 (2012)

13. R. Hou, Z.-Y. Guo, Journal of Building Materials, 16 (2013)

14. V.D. Galdina, Sulfur-extended asphalts, Omsk: SibADI (2011)

15. I.M. Rudenskaya, A.V. Rudenskiy, Organic Binders for Road Construction (1984)

16. F. Zhang, J.Y. Yu, S.P. Wu,Journal of Hazardous Materials 182, 507-517 (2010)

17. Polymer Modified Bitumen, Cambridge: Woodhead, 424(2011)

18. MCR 101 viscometer URL http://www.nocnt.ru/oborudovanie/laboratoriyaissledovaniya-fiziko-khimicheskikh-svojstv/17-viskozimetr-mcr101

19. SmartPave, http://www.anton-paar.com/uk-en/products/details/asphalt-rheometersmartpave/

20. Standard Test Method for Viscosity Determination of Asphalt at Elevated Temperatures Using a Rotational Viscometerhttps://www.astm.org/Standards/D4402.htm

21. P.C. Hiemenz, R. Rajagopalan, Marcel Dekker, 650(1997)

22. V.A. Gladkikh, E.V. Korolev, Online News of VolgGASU, 33(2014)

23. V.A. Gladkikh, E.V. Korolev, Advanced Materials Research, 1040 (2014)

24. A.P. Babichev, Physical Values(Energoatomizdat, Moscow,1991)

25. E.V. Korolev, Yu.M. Bazhenov, A.I. Al'bakasov, Radiation-protective and Chemicalresistant Sulfur Building Materials (IPK OGY, Orenburg, 2010)

26. E.V. Korolev, A.P. Proshin, Yu.M. Bazhenov, Yu.A. Sokolova, Radiation-protective and Corrosion-resistant Sulfur Building Materials (Paleotip, Moscow, 2004) 